\title{
HUBUNGAN SELF EFFICACY DENGAN PERILAKU SELF CARE PASIEN PASCA STROKE DI RUMAH SAKIT ISLAM SURABAYA
}

\author{
Ismatika, Umdatus Soleha \\ Fakultas Keperawatan dan Kebidanan \\ Universitas Nahdlatul Ulama Surabaya, Jln. Smea 57 Surabaya \\ Email: umdatus@unusa.ac.id
}

\begin{abstract}
The post-stroke can be regarded as the most difficult time for patients with post-stroke, they will experience a disability and inability to move as usual so that they will have difficulty in self care. The research was purposed to analyze the relationship of self-efficacy with self-care behavior of patients with post-stroke Islamic Hospital A Yani Surabaya. This study design was analytic correlation with cross sectional approach. The population of 36 people and a large sample of 36 respondents using purposive sampling technique. The independent variable of this research is self-efficacy and the dependent variable was self care behaviors. Instruments of research using questionnaires. Data analysis using the chi square test, significance value of a $=0.05$. The results showed that the majority of the 36 respondents, or 26 respondents $(72.2 \%)$ had good self efficacy and mostly or 27 respondents (75\%) had good self-care behaviors. The results of statistical test Chi Square $\rho=0.03<\alpha=0.05$ showed relationship between self-efficacy with self-care behavior of patients with post-stroke. The better self efficacy post-stroke patients, the better self-care behavior. Post-stroke patients should be able to prepare and improve the behavior of self care, so that patients can independently live aww life in the social environment well. The role of nurses in improving self-efficacy by preparing the skills, motivation and health education about self care.
\end{abstract}

Keyword : self efficacy, self care, pasca stroke patient

Abstrak: Pasca stroke bisa dikatakan sebagai masa yang paling sulit bagi penderita pasca stroke, mereka akan mengalami kecacatan dan ketidakmampuan dalam berwwaktivitas seperti sedia kala sehingga mereka akan mengalami kesulitan dalam self care. Tujuan penelitian untuk menganalisa hubungan self efficacy dengan perilaku self care pasien pasca stroke di Rumah Sakit Islam A Yani Surabaya. Desain penelitian ini adalah analitik korelasional dengan pendekatan cross sectional. Populasi sebesar 36 orang dan besar sampel sebesar 36 responden dengan teknik purposive sampling. Variabel independen penelitian ini adalah self efficacy dan variabel dependen adalah perilaku self care. Intrumen penelitian menggunakan kuesioner. Analisis data menggunakan uji chi square dengan, nilai kemaknaan $\alpha=0,05$. Hasil penelitian menunjukkan bahwa dari 36 responden sebagian besar atau 26 responden $(72.2 \%)$ memiliki self efficacy baik dan sebagian besar atau 27 responden (75\%) memiliki perilaku self care baik. Hasil uji statistik chi square $\rho=0.03<\alpha=0.05$ menunjukkan ada hubungan antara self efficacy dengan perilaku self care pasien pasca stroke. Semakin baik self efficacy pasien pasca stroke maka perilaku self care semakin baik. Pasien pasca stroke sebaiknya dapat mempersiapkan dan meningkatkan perilaku self care, sehingga pasien dapat secara mandiri menjalai kehidupan di lingkungan sosial 
dengan baik. Peran perawat dalam meningkatkan self efficacy dengan mempersiapkan keterampilan, motivasi dan memberikan pendidikan kesehatan tentang self care.

Kata kunci : self efficacy, self care, pasien pasca stroke

\section{PENDAHULUAN}

Stroke merupakan kegawatan neurologi yang serius menduduki peringkat tinggi sebagai penyebab kematian. WHO mendefinisikan stroke merupakan suatu tanda klinis yang berkembang cepat akibat gangguan otak fokal (atau global) dengan gejala-gejala yang berlangsung selama 24 jam atau lebih dan dapat menyebabkan kematian tanpa adanya penyebab lain yang jelas selain vaskuler menurut Kabi G.Y.C.R, Tumewag R, Kembuan M.A.H.N (2015). Menurut Dourman, Karel (2013) Setelah stroke, sel otak mati dan hematom yang terbentuk akan diserap kembali secara bertahap. Proses alami ini selesai dalam waktu 3 bulan..

Dampak stroke sekitar $80 \%$ terjadi penurunan parsial/total gerakan lengan dan tungkai, $80-90 \%$ bermasalah dalam berpikir dan mengingat, $70 \%$ menderita depresi, $30 \%$ mengalami kesulitan bicara, menelan, membedakan kanan dan kiri. Hal ini akan berdampak terhadap menurunnya tingkat produktifitas serta dapat mengakibatkan terganggunya sosial ekonomi keluarga menurut Dourman, Karel (2013). Karena pasien dengan pasca stroke sebagian besar mengalami kelemahan pada motoriknya menyebabkan mereka mengalami penurunan kemampuan untuk melakukan perawatan diri, sehingga mereka akan memerlukan bantuan dari keluarga ataupun orang lain untuk memenuhi kebutuhannya.

Data WHO 2016 diperkirakan 17,5 juta orang meninggal karena cardiovascular disease (CVDs) pada tahun 2012 mewakili $31 \%$ dari seluruh kematian global, diperkirakan 7,4 juta adalah karena penyakit jantung koroner dan 6,7 juta karena stroke.. Berdasarkan laporan kementerian kesehatan RI tahun 2014 jumlah penderita penyakit stroke di Indonesia tahun 2013 berdasarkan diagnosis tenaga kesehatan diperkirakan sebanyak 1.236 .825 orang atau $(7,0 \%)$ sedangkan penderita penyakit stroke di provinsi Jawa Timur berdasarkan diagnosis Nakes sebanyak 190.449 orang atau $(6,6 \%)$ menurut Kemenkes RI (2014) dalam Zuhrotul, Haidah (2014). Di Rumah Sakit Umum Dr Soetomo Surabaya pada tahun 20012010 sebesar 1.000 pasien per tahun, namun pada tahun 2011 jumlah pasien meningkat menjadi 1.600 pasien per tahun menurut Sukarelawati E (2012).

Menurut data di Poli saraf Rumah sakit Islam Surabaya pada bulan September-November 2016 jumlah pasien pasca stroke adalah 110 pasien. Jumlah pasien pasca stroke yang mengikuti rehabilitasi di poli saraf (fisioterapi) Rumah Sakit Islam A. Yani Surabaya 2016 adalah 36 pasien (ratarata satu bulan). Menurut data rekam medis usia pasien pasca stroke yang mengikuti rehabilitasi stroke berkisar 43-70 tahun. Menurut data rekam medis pasien pasca stroke di poli saraf Rumah Sakit Islam A Yani Surabaya sebesar 75 $\%$ pasien mengalami kelemahan motorik, $5 \%$ susah menelan, 2\% gangguan $\mathrm{BAB}, 13 \%$ nyeri tangan, dan $5 \%$ mengalami pelo.

Pasca stroke bisa dikatakan sebagai masa yang paling sulit bagi penderita pasca stroke, mereka akan mengalami kecacatan dan ketidakmampuan dalam beraktivitas seperti sedia kala. Salah satunya adalah ketidakmampuan untuk melakukan perawatan diri (Self Care). Adapun 
dalam proses rehabilitasi, pasien pasca stroke akan dilatih oleh perawat rehabilitasi untuk membantu mengembalikan fungsi motorik yang terganggu akibat stroke. Dalam hal ini diharapkan pasien pasca stroke mampu melakukan aktivitas dan self care secara mandiri untuk mencegah terjadinya ketergantuan akibat kecacatan setelah stroke.

Menurut penelitian Fadlulloh, S. et al. 2014 beberapa aktivitas pada pasien pasca stroke yang memerlukan bantuan orang lain meliputi kebersihan diri, mandi, toilet, menaiki tangga, memakai pakaian, mengontrol BAK, berpindah tempat, dan berpindah dari kursi ke tempat tidur. Namun, bantuan yang terus menerus dapat berdampak pada perilaku self care pasien. Menurut Orem, Dorothea et al (2001) dalam Ramawati, Dian., et al (2012) self care (perawatan diri sendiri) adalah aktivitas dan inisiatif oleh individu itu sendiri dalam memenuhi serta mempertahankan kehidupan, kesehatan dan kesejahteraan. Dalam hal pasien pasca stroke akan sering mengalami keputusasaan sampai depresi karena orang-orang disekitarnya sering menganggap bahwa dirinya tidak mampu melakukan apapun terutama dalam hal Self care. Faktor-faktor yang mempengaruhi perilaku self care menurut middle range theory of chronic illness yaitu: pengalaman dan keterampilan, motivasi, keyakinan dan nilai budaya, confidence (keyakinan) meliputi: self efficacy, self esteem, kebiasaan, kemampuan fungsional dan kognitif, dukungan sosial, serta fasilitas. Upaya untuk mencegah keputusasaan pada pasca stroke, adalah dengan memiliki suatu Self efficacy (keyakinan) yang besar. Self Efficacy adalah keyakinan individu terhadap kemampuannya melakukan suatu bentuk perilaku yang spesifik dan tetap melakukan sebuah perilaku walaupun terdapat rintangan (Riegel, 2012). Self efficacy ini sangat penting karena dapat mempengaruhi perilaku seseorang terutama perilaku self care. Apabila pasien pasca stroke memiliki keyakinan yang besar dan kuat dalam melakukan self care (perawatan diri), maka akan membantu pemulihan motorik dan kepercayaan diri pasien pasca stroke sehingga pasien pasca stroke akan berusaha melakukan self care dalam kesehariannya.

Perawat sebagai salah satu tenaga kesehatan, memiliki peranan yang strategis dalam memberikan kemampuan kepada keluarga dan pasien dalam melakukan penanganan secara mandiri. Sejumlah penelitian eksperimental memperlihatkan bahwa perawat mempunyai peran yang cukup berpengaruh terhadap perilaku pasien (Tagliacozzo D.M.,et al., (1974) dalam Sutandi, Aan (2012). Peran perawat dalam aplikasi teori self care Orem adalah membantu meningkatkan kemampuan pasien untuk mandiri pada area klinis yangakan meningkatkan kualitas hidup saat pasien berada pada area komunitas menurut penelitian Ropyanto, Chandra Bagus (2014). Dengan pemahaman yang benar dan memberdayakan keluarga dan pasien memiliki derajat kesehatan yang optimal. Perawat-perawat yang bertugas di tempat rehabilitasi pasca stroke sangat berperan aktif meningkatkan self efficacy pasien pasca stroke yang mempengaruhi peningkatan self care.

Tujuan penelitian ini menganalisa hubungan self efficacy dengan perilaku self care pasien pasca stroke di Rumah Sakit Islam A Yani Surabaya.

\section{METODE}

Disain penelitian yang digunakan adalah analitik korelasional dengan pendekatan cross sectional, yaitu suatu penelitian dimana variabel independen 
penelitian ini adalah self efficacy dan variabel dependen adalah perilaku self care yang diobservasi sekaligus dalam waktu yang sama. Populasi pada penelitian ini adalah 36 orang. Besar sampel penelitian yaitu 36 responden yang diambil secara nonprobability sampling dengan tehnik purposive sampling.

Data dianalisis menggunakan uji statistik Chi Square dengan kemaknaan $\alpha=0,05$, dengan bantuan SPSS bila didapatkan $\rho<\alpha$ maka $\mathrm{H}_{0}$ ditolak artinya ada hubungan self efficacy dengan perilaku self care pasien pasca stroke di Rumah Sakit Islam A Yani Surabaya.

\section{HASIL DAN PEMBAHASAN}

1. Hasil Penelitian

a. Data Umum

Dalam data umum ini didalamnya meliputi karakteristik responden yang didapat dari hasil penelitian pada pasien pasca stroke di Rumah Sakit Islam A.Yani Surabaya.

1) Karakteristik responden berdasarkan umur

Karakteristik responden berdasarkan umur pada pasien pasca stroke di Rumah Sakit Islam A.Yani Surabaya dapat dilihat pada tabel 5.1 sebagai berikut:

Tabel 5.1 Distribusi frekuensi responden berdasarkan umur di Rumah Sakit Islam A.Yani Surabaya pada bulan Februari 2017

\begin{tabular}{llll}
\hline No. & Umur (tahun) & Frekuensi & $\begin{array}{l}\text { Persentase } \\
(\%)\end{array}$ \\
\hline 1. & $\begin{array}{l}\text { Dewasa akhir } \\
(>60)\end{array}$ & 12 & 33,3 \\
2. & $\begin{array}{l}\text { Dewasa madya } \\
(41-60)\end{array}$ & 23 & 63,9 \\
$3 . \quad \begin{array}{l}\text { Dewasa awal } \\
(18-40)\end{array}$ & 1 & 2,8 \\
\hline Total & & 36 & 100 \\
\hline
\end{tabular}

Data Primer 13 Februari 2017

Dari data yang ada pada tabel 5.1 Menunjukkan bahwa dari 36 responden terdapat sebagian besar $(63,9 \%)$ berusia dewasa madya (41-60 tahun).

2) Karakteristik responden berdasarkan lama pengobatan

Karakteristik responden berdasarkan lama pengobatan pada pasien pasca stroke di Rumah Sakit Islam A.Yani Surabaya terdiri dari lama pengobatan $>1$ tahun dan lama pengobatan $<1$ tahun yang dapat dilihat ditabel 5.4 sebagai berikut:

Tabel 5.4 Distribusi frekuensi responden berdasarkan lama pengobatan di Rumah Sakit Islam A. Yani Surabaya, Februari 2017

\begin{tabular}{llll}
\hline No. & $\begin{array}{l}\text { Lama } \\
\text { Pengobatan }\end{array}$ & Frekuensi & $\begin{array}{l}\text { Persentase } \\
(\%)\end{array}$ \\
\hline 1. & $>1$ tahun & 5 & 13,9 \\
2. & $<1$ tahun & 31 & 86,1 \\
\hline Jumlah & 36 & 100 \\
\hline
\end{tabular}

Data Primer 13 Februari 2017

Dari data yang ada pada tabel 5.4 menunjukkan hasil bahwa dari 36 responden terdapat hampir seluruhnya $(86,1 \%)$ dengan jangka waktu pengobatannya $<1$ tahun.

1. Data Khusus

a. Self efficacy

Karakteristik responden berdasarkan self efficacy pada pasien pasca stroke di Rumah Sakit A.Yani Surabaya terdiri dari self efficacy baik dan self efficacy tidak baik yang dapat dilihat pada tabel 5.5 sebagai berikut:

Tabel 5.5 Distribusi frekuensi responden berdasarkan self efficacy di Rumah Sakit Islam A.Yani Surabaya, Februari 2017

\begin{tabular}{llll}
\hline No. & $\begin{array}{l}\text { Self } \\
\text { Efficacy }\end{array}$ & Frekuensi & $\begin{array}{l}\text { Persentase } \\
(\%)\end{array}$ \\
\hline 1. & Baik & 26 & 72,2 \\
2. & Tidak baik & 10 & 27,8 \\
\hline Total & & 36 & 100 \\
\hline
\end{tabular}

Data Primer 13 Februari 2017

Dari data yang ada pada tabel 5.5 menunjukkan bahwa dari 36 responden 
terdapat sebagian besar $(72,2 \%)$ memiliki self efficacy baik.

b. Perilaku self care

Karakteristik responden berdasarkan perilaku self care pada pasien pasca stroke di Rumah Sakit Islam A Yani Surabaya terdiri dari self care baik dan self care kurang yang dapat dilihat pada tabel 5.6 sebagai berikut:

Tabel 5.6 Distribusi frekuensi responden berdasarkan perilaku self care di Rumah Sakit Islam A.Yani Surabaya, Februari 2017

\begin{tabular}{llll}
\hline No. & $\begin{array}{l}\text { Self } \\
\text { Care }\end{array}$ & Frekuensi & $\begin{array}{l}\text { Persentase } \\
(\%)\end{array}$ \\
\hline 1. & Baik & 27 & 75 \\
2. & Kurang & 9 & 25 \\
\hline Total & 36 & 100 \\
\hline
\end{tabular}

Data Primer 13 Februari 2017

Dari data yang ada pada tabel 5.6 menunjukkan bahwa dari 36 responden terdapat sebagian besar (75\%) memiliki perilaku self care baik.

c. Hubungan self efficacy dengan perilaku self care pasien pasca stroke di Rumah Sakit Islam A.Yani Surabaya

Tabel 5.7 Tabulasi silang hubungan self efficacy dengan perilaku self care pasien pasca stroke di Rumah Sakit Islam A.Yani Surabaya, Februari 2017

\begin{tabular}{|c|c|c|c|c|c|c|}
\hline \multirow{3}{*}{$\begin{array}{l}\text { Self } \\
\text { efficacy }\end{array}$} & \multicolumn{4}{|c|}{ Self care } & \multirow{2}{*}{\multicolumn{2}{|c|}{ Total }} \\
\hline & \multicolumn{2}{|c|}{ Baik } & \multicolumn{2}{|c|}{ Kurang } & & \\
\hline & $\mathrm{N}$ & $\%$ & $\mathrm{~N}$ & $\%$ & $\mathrm{~N}$ & $\%$ \\
\hline Baik & 23 & 88,5 & 3 & 11,5 & 26 & 100 \\
\hline Tidakbaik & 4 & 40 & 6 & 60 & 10 & 100 \\
\hline Jumlah & 27 & 75 & 9 & 25 & 36 & 100 \\
\hline
\end{tabular}

Data Primer 13 Februari 2017

Dari data yang ada pada tabel 5.7 menunjukkan bahwa dari 26 responden sebesar 23 responden yang memiliki self efficacy baik, hampir seluruhnya $(88,5 \%)$ memiliki self care baik dan dari 10 responden yang memiliki self efficacy tidak baik, sebagian besar $(60 \%)$ memiliki self care kurang.

Hasil uji Statistik Chi Square dengan nilai kemaknaan $\alpha=0,05$. Didapatkan nilai $\rho=0,03$ yang berarti $\rho$ $<\alpha$ maka $\mathrm{H}_{0}$ ditolak artinya ada hubungan self efficacy dengan perilaku self care pasien pasca stroke di Rumah Sakit Islam A.Yani Surabaya.

2. Pembahasan

a. Self efficacy pada pasien pasca stroke

Berdasarkan tabel 5.5 menunjukkan bahwa dari 36 responden terdapat sebagian besar $(72,2 \%)$ memiliki self efficacy baik, yang dapat mempengaruhi perilaku self care pasien yaitu dengan memiliki keyakinan bahwa klien mampu melakukan aktifitas seharihari secara mandiri sesuai dengan kuesioner SSEQ (Stroke Self Efficacy Quesionnaire). Berdasarkan hasil kuesioner menunjukkan bahwa dari 36 responden terdapat $16,3 \%$ memiliki keyakinan untuk berpindah dari tempat tidur secara mandiri, 16,4\% memiliki keyakinan untuk berjalan-jalan dirumah, 16,8\% memiliki keyakinan untuk makan dan menyiapkan makan secara mandiri, $17 \%$ memiliki keyakinan untuk memakai pakaian sendiri, $16 \%$ memiliki keyakinan untuk melaksanakan program lanjutan dalam mencapai kesembuhan, dan $17 \%$ memiliki keyakinan untuk mengontrol frustasi. Persentase rata-rata self efficacy pada pasien post stroke yang paling tinggi dari keenam komponen kuesioner SSEQ (Stroke Self Effioacy Quesionnaire) yaitu keyakinan untuk memakai pakaian dan mengontrol frustasi karena menurut Sari, W, Indrawati L \&Dewi G.S (2008) pada penderita stroke dimana terdapat kelemahan pada separuh badannya, berpakaian dilakukan pada sisi yang lemah lebih dulu dengan dibantu oleh anggota gerak yang sehat, setelah itu 
diikuti dengan memakaikan pakaian pada sisi tubuh yang sehat.Self efficacy didefinisikan sebagai keyakinan diri pada seseorang yang mampu menentukan dalam berperilaku menurut Pajares (2002), dalam Werrel (2011) dalam Muin dkk (2015). Menurut Bandura (1997) dalam Rustika, I Made (2012) Pada teori sosial kognitif, rendahnya Self Efficacy dapat menyebabkan meningkatnya kecemasan dan perilaku menghindar. Individu akan menghindari aktivitas-aktivitas yang dapat memperburuk keadaan, hal ini bukan disebabkan oleh ancaman tapi karena merasa tidak mempunyai kemampuan untuk mengelola aspekaspek yang beresiko. Orang yang memiliki Self Efficacy yang tinggi maka tingkat stresnya akan rendah, dan sebaliknya orang yang memiliki Self Efficacy yang rendah maka tingkat stresnya akan tinggi, individu tersebut mudah mengalami distress dan frustasi.

Terdapat empat mekanisme psikologis yang dikaitkan dengan self efficacy dan perilaku yang tampak, yaitu: a) self efficacy dinilai dapat menurunkan kecemasan seiring dengan rangsangan fisiologisnya, b) seseorang dengan self efficacy tinggi akan mampu mendistraksi atensinya dari sensasi fisiologis yang mengancam, c) seseorang dengan self efficacy yang memadai merasa distress pada sensasi fisik, namun berupaya untuk menghadapinya, d) sensasi fisik yang diabaikan maupun menimbulkan distress, individu dapat memaknai dengan mengubah interpretasinya (Turk \& Okifuji, 2002 dalam Haryanti, Luh Putu Suta, 2012 dalam Latifah Maf'ul (2016)).

Dalam suatu aktivitas yang melibatkan kekuatan dan stamina, seseorang akan mengalami kelelahan dan rasa sakit, dalam hal ini akan berkaitan juga dengan keadaan fisiologis dan suasana hati, ada empat cara untuk merubah Self Efficacy, yaitu a) Meningkatkan kondisi tubuh, b) Menurunkan stres, c) mengubah emosi negatif, dan d) mengoreksi kesalahan interpretasi terhadap keadaan tubuh (Bandura,(1997) dalam Rustika I Made (2012).

Faktor yang mempengaruhi self efficacy pada pasien stroke adalahusia, tingkat pendidikan, pekerjaan. Hasil tabel 5.1 menunjukkan bahwa dari 36 responden terdapat sebagian besar $(63,9 \%)$ berusia dewasa madya (41-60 tahun). Individu yang memiliki usia pertengahan lebih sering mengalami perubahan fisik dan mental, dalam hal ini individu lebih rentan mengalami sakit, mereka memiliki tekad untuk berusahamenyelesaikan permasalahan dengan mencapai suatu tujuan yang diinginkan, dalam hal ini berupa kesehatan. Pada aktivitas mencapai kesuksesan dalam menyelesaikan suatu masalah,Individu tersebut dapat meningkatkan self efficacy yang mampu mempertahankan dan meningkatkan kesehatannya. Hal ini sesuai dengan teori Wantiyah (2010) seiring dengan perkembangan usia dewasa, semakin banyaknya permasalahan tingkat stressor yang dapat mempengaruhi self efficacy seorang individu.

Hasil penelitian pada Tabel 5.2 menunjukkan bahwa dari 36 responden terdapat hampir setengahnya $(47,2 \%)$ berpendidikan Menengah (SMA sederajat).Pendidikan seseorang sangat penting dalam menyelesaikan permasalahan, dalam hal ini tingkat pendidikan mempengaruhi perilaku khususnya pengetahuan dibidang kesehatan. Menurut (Wu et al, 2006) dalam Latifah Maf'ul (2016) Tingkat pendidikan merupakan indikator seseorang dalam menempuh jenjang pendidikan formal dan umumnya 
berpengaruh terhadap kemampuan dalam mengolah informasi, sehingga individu yang berpendidikan tinggi memiliki self efficacy yang lebih baik. Dalam hal ini sesuai dengan teori Notoadmodjo, 2007 dalam Widiawaty N, 2011 Semakin tinggi tingkat tingkat pendidikan formal semakin mudah meyerap informasi kesehatan, semakin tinggi pula kesadaran untuk berperilaku sehat.

Hasil peneitian pada Tabel 5.3 menunjukkan bahwa dari 36 responden terdapat sebagian besar $(63,9 \%)$ merupakan tidak bekerja. Menurut hasil wawancara peneliti dengan sebagian kecil responden bahwa setelah mengalami stroke pasien mengalami kelemahan fisik sehingga responden lebih fokus untuk meningkatkan derajat kesehatannya dengan rajin menjalani terapi medis, dan sebagian besar responden sudah melewati masa pensiun. Hal ini sesuai dengan teori Bandura (1997) dalam Rustika I Made (2012) self efficacy akan meningkat jika dalam kehidupan seseorangdapat berhasil menyelesaikan suatu masalah, karena apabila seseorang melihat orang lain mencapai keberhasilan self care dalam meningkatkan kemandirianpada aktivitas sehari-hari maka self efficacy seseorang akan meningkat untuk melakukan hal yang sama walaupun terdapat rintangan.

b. Perilaku self care pada pasien pasca sroke

Berdasarkan Tabel 5.6 menunjukkan bahwa dari 36 responden terdapat sebagian besar $(75 \%)$ memiliki perilaku self care baik. Berdasarkan hasil kuesioner Barther Index of Activities of daily livingtentang perilaku self care pada pasien pasca stroke menunjukkan bahwa dari 36 responden memilikirata-rata $\quad 3,47 \quad$ dengan presentase $34,7 \%$ dari hasil kuesioner Barther Index of Activities of daily living. Perilaku self care yang dilakukan oleh klien pasca stroke merupakan aktivitas perawatan diri yang terdiri dari aktivitas mandi, berpakaian, toileting, jalan-jalan, berdandan, makandan berpindah yang sering dilakukan responden dengan inisiatif dan usaha secara mandiri dalam aktivitas seharihari, yang dapat diukur dengan kuesioner Barther Index of Activities of daily living. Self care pada pasien dengan penyakit kronis seperti stroke merupakan hal yang kompleks dan sangat dibutuhkan untuk keberhasilan mengontrol dari penyakit kronis tersebut. Karena pada penyakit stroke akan mudah terjadi kecacatan apabila tidak melakukan aktivitas.Bagi klien pasca stroke, tindakan self care tercermin pada aktivitas mereka dalam gaya hidup yang direkomendasikan seperti mengkonsumsi makanan yang dianjurkan, dan menjahui perilaku yang beresiko menimbulkan masalah, melaksanakan aktivitas sehari-hari yang disarankan, dan selalu menjalankan kegiatan ibadah yang meningkatkan spiritualitas, serta selalu berfikir positif.

Hal ini sesuai dengan teori self care, Orem mengemukakan bahwa self care meliputi : pertama, self care itu sendiri yang merupakan aktivitas dan inisiatif dari individu serta dilaksanakan oleh individu itu sendiri dalam memenuhi serta mempertahankan kehidupan, kesehatan serta kesejahteraan; kedua self care agency merupakan suatu kemampuan individu dalam melakukan perawatan diri sendiri, yang dapat dipengaruhi oleh usia, perkembangan, sosiokultural, kesehatan dan lain-lain; ketiga adanya tuntutan atau permintaan dalam perawatan diri sendiri dengan menggunakan metode dan alat dalam tindakan yang tepat; keempat, kebutuhan self care merupakan suatutindakan yang ditujukan pada penyediaan dan 
perawatan diri sendiri yang bersifat universal dan berhubungan dengan proses kehidupan manusia serta dalam upaya mempertahankan fungsi tubuh, self care yang bersifat universal itu adalah aktivitas sehari-hari atau activity daily living (ADL) dengan mengelompkkan ke dalam kebutuhan dasar manusianya menurut Hidayat, A Aziz Alimul (2011).

Perilaku self care dipengaruhi oleh pengalaman dan keterampilan, motivasi, keyakinan dan nilai-nilai budaya, confidence (keyakinan), kebiasaan, kemampuan fungsional dan kognitif, dukungan sosial, dan fasilitas Menurut Riegel, Barbara (2012). Berdasarkan tabel 5.4 menunjukkan bahwa dari 36 responden terdapat hamper seluruhnya $(86,1 \%)$, lama pengalaman rehabilitasi pada pasien pasca stroke kurang dari satu tahun. maka dapat mempengaruhi keterampilan perilaku self care dalam kehidupan sehari-hari sehingga dapat mempertahankan dan meningkatkan status kesehatannya. Hal ini sesuai dengan teori Bai et al (2009) bahwa klien yang memiliki pengalaman dengan penyakit kronis yang lebih lama dapat lebih memahami tentang hal terbaik yang harus dilakukan untuk mempertahankan status kesehatannya, yaitu salah satunya dengan aktifitas self care. Klien yang memiliki pemahaman adekuat tentang pentingnya self care maka dapat dijadikan sebagai dasar bagi mereka untuk mencari informasi yang seluas-luasnya tentang perawatan diri melalui berbagai cara dan sumber informasi.

c. Hubungan self efficacy dengan perilaku self care pasien pasca stroke di Rumah Sakit Islam A Yani Surabaya

Berdasarkan hasil uji statistik terhadap hubungan self efficacy dengan perilaku self care pada pasien pasca stroke melalui uji chi square dengan menggunakan program SPSS 23for windows, hasil yang didapatkan $\rho=$ 0.03 dengan nilai kemaknaan $\alpha=0,05$ yang berarti $\rho<\alpha$ maka $\mathrm{H}_{0}$ ditolak artinya ada hubungan self efficacy dengan perilaku self care pasien pasca stroke di Rumah Islam A Yani Surabaya.

Tabel 5.7 menunjukkan bahwa dari 36 responden sebesar 23 responden yang memiliki self efficacy baik, hampir seluruhnya $(88,5 \%)$ memiliki self care baik dan dari 10 responden yang memiliki self efficacy tidak baiksebagian besar $(60 \%)$ memiliki self care kurang. Hasil tersebut menunjukkan bahwa pasien pasca stroke yang mempunyai self efficacy baik memiliki perilaku self care yang baik, sehingga mampu mencapai derajat kesehatan yang lebih baik..

Menurut Octary (2007) dalam Prestiana, Novita Dian Iva \& Dewanti Purbandini (2012) seseorang yang memiliki self efficacy tinggi percaya bahwa mereka akan dapat menanggulangi kejadian dan situasi secara efektif. Tingginya self efficacy menurunkan rasa takut akan kegagalan, meningkatkan aspirasi, meningkatkan cara penyelesaian masalah, dan kemampuan berfikir analitis. Menurut bandura orang yang memiliki self efficacy yang tinggi akan mempunyai semangat yang lebih tinggi di dalam menjalankan suatu tugas tertentu dibandingkan dengan orang yang memiliki self efficacy yang rendah.

Perilaku self care merupakan hal yang penting pada pasien pasca stroke, yaitu dengan berusaha melakukan aktivitas sehari-hari secara mandiri sehingga klien dapat mempertahankan dan meningkatkan derajat kesehatannya.Self care sangat dipengaruhi oleh sikap dan keyakinan 
seperti self efficacy. Keyakinan terhadap kemampuan untuk melakukan self care merupakan penting disetiap proses self care untuk mencapai keberhasilan self care..

Pasien pasca stroke yang mengalami kelemahan motorik akan berusaha mengelola dan mengontrol dengan melakukan perilaku self care untuk mempertahankan dan meningkatkan derajat kesehatnnya. Perilaku self care secara mandiri tersebut akan menjadi tugas bagi pasien pasca stroke baik yang sedang dan sesudah mendapatkan terapi rehabilitasi ataupun ketika di rumah sehingga pasien akan selalu memperhatikan self care dalam kehidupan sehari-hari (Kusniawati, 2011).

\section{SIMPULAN DAN SARAN}

1. Simpulan

Terdapat hubungan yang signifikan antara self efficacy dengan perilaku self care pasien pasca stroke di Rumah Sakit A Yani Surabaya.

2. Saran

a. Pasien pasca stroke secara rutin untuk melakukan self care (perawatan diri) secara mandiri untuk mencegah kecacatan, dapat meningkatkan kepercayaan diri dan kemandirian sehingga mampu meningkatkan kesejahteraan dan status kesehatan.

b. Meningkatkan peran perawat dalam program pendidikan kesehatan terkait dengan perilaku self care terutama tentang anjuran melakukan aktivitas sehari-hari secara mandiri dan kepatuhan jadwal terapi medis kepada pasien pasca stroke.

\section{DAFTAR PUSTAKA}

Alligood, M.R. and Tomey, A. M. (2006). Nursing Theorists and Their Work. Ed. 6. Missouri, Mosby.
Auryn,Virzara. (2007). Mengenal \&Memahami Stroke. Jogjakarta, Katahatia

Ariani, Tutu April. (2012). Sistem Neurobehaviour. Jakarta, Salemba Medika

Bandura, A. (2009). Self Efficacy : The Exercise Of Control, W.H. Freeman and company. New York.

Black, Joyce M. Black. (2014). Keperawatan Medikal Bedah: Manajemen Klinisuntuk Hasil yang Diharapkan.Singapura, Elsevier

Dourman, Karel. (2013). Waspada Stroke Usia Muda. Jakarta, Cerdas Sehat

Fadlulloh, S., Upoyo A.S., Hartanto Y. (2014). Hubungan Tingkat ketergantungan dalam Pemenuhan Aktivitas Kehidupan Sehari-Hari (AKS) dengan harga diri Penderita Stroke di Poliklinik Syaraf RSUD Prof.Dr.Margono Soekarjo Purwokerto. Jurnal keperawatan Soedirman

Hidayat, A Aziz Alimul. (2011). Pengantar Konsep Dasar Keperawatan edisi 2. Jakarta, Salemba Medika

Kabi G.Y.C.R, Tumewah R, Kembuan M.A.H.N. (2015). Gambaran Faktor Resiko Pada Penderita Stroke Iskemik yang Dirawat Inap Neurologi RSUP Prof. Dr.R.D.Kndau Manado Periode Juli 2012-Juni 2013.Jurnsl eClinic(eCl) Vol 3, No 1

Kowalak. (2014). Buku Ajar Patofisiologi. Jakarta, EGC

Kozier. (2011). Buku Ajar Fundamental Keperawatan Konsep, Proses \& Praktik. Jakarta, EGC

Kusniawati. (2011). Analisis Faktor yang Berkontribusi Terhadap Self Care Diabetes pada Klien Diabetes Melitus Tipe 2 di Rumah 
Sakit Umum Tanggerang. Tesis. Depok : Fakultas Ilmu Keperawatan, UI

Latifah, M. (2016). Hubungan Self Efficacy dengan Perilaku Self Care Pasien Kanker Payudara di Rumah Sakit Ongkologi Surabaya. Surabaya, Fakultas Keperawatan dan Kebidanan Universitas Nahdlatul Ulama Surabaya

Mendrofa, Fery Agusman. (2015). Independency Models of Nursing Self-Care for Ischemic Stroke Patient. International Journal of Public Health Science (IJPHS) Vol 4, No 2: June 2015 page. 8893: Institute of Advanced Engineering and Science

Maujen. (2011). An Investigation of the Relationship Between Self Efficacy \& Well-Being in Stroke Survivors. Tesis. Griffith University

Nursalam. (2016). Metodologi Penelitian Ilmu Keperawatan : Pendekatan Praktis. Jakarta, Salemba Medika

Orem, Dorothea E, Susan G Taylor, Kathie McLaughin Renpenning. (2001) .Nursing Concepts of Practice.America, Mosby

Prestiana, Novita Dian Iva \& Dewanti Purbandini. 2012. Hubungan Antara Efikasi Diri (Self Efficacy) \& Stres Kerja Dengan Kejenuhan Kerja (Burnout) Pada Perawat IGD Dan ICU RSUD Kota Bekasi. Jurnal Soul, Vol. 5, No.2

Potter \& Perry. (2009). Fundamental of Nursing: Fundamental Keperawatan edisi 7. Jakarta, Salemba Medika

Qamal L. (2015). Faktor-faktor Risiko Penyebab Stroke pada Pasien Di Ruang Geulima 1 Rumah Sakit Umum Daerah Sr Zainoel Abidin Banda Aceh. Skripsi, Fakultas Keperawatan Universitas Syiah Kuala Banda Aceh
Rahmawati D., Allenidekania., Besral. (2012). Kemampuan Perawatan Diri Anak Tuna Grahita Berdasarkan Faktor Eksternal dan Internal Anak. Jurnal Keperawatan Indonesia Vol 15, No 2

Riegel, Barbara et al. (2012). A MiddleRange Theory of Self Care of Chronic Illness. Nursing Science. (35), 3, 194-204.

Rosjidi, Cholik Harun \& Saiful Nurhidayat. (2014). Buku Ajar Peningkatan Tekanan Intrakranial \& Gangguan Peredaran Darah Otak. Yogyakarta, Gosyen Publishing

Rustika, I.M. (2012). Efikasi Diri: Tinjauan Teori Albert Bandura, Buletin Psikologi Vol 20 No.1-2. Yogyakarta : Fakultas Psikologi Universitas Gadjah Mada.

Sari, Wening, dkk. (2008). Care YourSelf, Stroke. Jakarta, Penebar Plus

Sukarelawati E. (2012). Pasien Stroke Di Surabaya Meningkat Setiap Tahun. www.antarajatim.com. Artikel di akses 9 Juli 2012

Sugiyono. (2012). Metode Penelitian Kuantitatif, Kualitatif, dan $R \& D$. Bandung, Alfabeta Cv

Widyastuti S. (2006).Kumpulan Instrumen Penelitian Kesehatan. Jakarta, EGC

Wahyu, G.G. (2009). Stroke Hanya Menyerang Orang Tua?. Yogyakarta, B First

Widiawaty, N. (2011). Hubungan Tingkat Pendidikan Formal dan Tingkat Pengetahuan Wanita tentang Kanker Payudara dengan Kejadian Kanker Payudara di Borokulon Banyuurip Purworejo. Jurnal Komunikasi Kesehatan Ed 3 Vol 2 No 02 P3M Purworejo. 